\title{
Avaliação da eficiência de diferentes formas de controle da queima das folhas do inhame causada por Curvularia eragrostides
}

\author{
Valdeir Nunes Carvalho ${ }^{1}$, Edna Peixoto da Rocha Amorim² ${ }^{2}$, Georgia de Souza Peixinho ${ }^{3}$ []
}

'Doutorando do Programa de Pós-graduação em Agronomia: Proteção de plantas pela Universidade Estadual Paulista "Júlio Mesquita Filho" (UNESP), Campus Botucatu, Faculdade de Ciências Agronômicas, (FCA), CEP 18610-034, Botucatu, SP, Brasil. ${ }^{2}$ Docente da Universidade Federal de Alagoas, Centro de Ciências Agrárias, CEP 57080-000, Rio Largo, AL, Brasil. ${ }^{3}$ Doutoranda no Programa de Pós-graduação em Agronomia: Proteção de Plantas da Universidade Federal de Alagoas, Centro de Ciências Agrárias, CEP: 57080-000. Rio Largo, AL, Brasil.

Autor para correspondência: Valdeir Nunes Carvalho (valdeirnunes4@gmail.com)

Data de chegada: 20/06/2017. Aceito para publicação em: 04/11/2020.

$10.1590 / 0100-5405 / 181645$

\section{RESUMO}

Carvalho, V.N.; Amorim, E.P.R.; Peixinho, F.S. Avaliação da eficiência de diferentes formas de controle da queima das folhas do inhame causada por Curvularia eragrostides. Summa Phytopathologica, v.47, n.1, p.34-37, 2021.

A queima das folhas do inhame, causada por Curvularia eragrostides pode comprometer a produção do inhame (Dioscorea spp.), uma cultura de extrema importância para a região Nordeste do Brasil. O uso de produtos naturais vem sendo utilizados com eficiência no controle de doenças de plantas por sua ação fungitóxica ou pela presença de compostos eliciadores, reduzindo o uso de defensivos agrícolas. O objetivo deste trabalho foi avaliar o efeito de diferentes formas de controle da queima das folhas do inhame causado por C. eragrostides. Foi analisada a esporulação de C. eragrostides em placas de Petri contendo meio BDA com os seguintes produtos: manipueira ( $40 \%$ ); óleo de hortelã $(100 \mu \mathrm{L} / \mathrm{mL})$, extratos de alho, e de melão de São Caetano, folha de inhame (20\%), Ecolife ${ }^{\circledR}(2 \%)$; Trichoderma sp. $\left(2,0\right.$ g. $\left.\mathrm{L}^{-1}\right)$; acibenzolar-S-metil $\left(0,15\right.$ g. $\mathrm{L}^{-1}$ e 0,3 g. $\left.\mathrm{L}^{-1}\right)$, separadamente. A testemunha foi placa com meio BDA sem adição de produto. A avaliação do efeito preventivo dos produtos in vivo, sobre o desenvolvimento da doença foi realizada com tratamentos selecionados no ensaio in vitro. Nesse ensaio in vivo as plantas de inhame cv. Da Costa, com 45 dias de idade foram pulverizadas 48 e $72 \mathrm{~h}$ antes da inoculação do patógeno com óleo de hortelã $(100 \mu \mathrm{L})$, extratos de alho e de folhas de inhame (20\%); Trichoderma $\mathrm{sp}$. $\left(2,0 \mathrm{~g} \cdot \mathrm{L}^{-1}\right) ; \operatorname{ASM}\left(0,15\right.$ e $\left.0,3 \mathrm{~g} \mathrm{~L}{ }^{-1}\right)$ e água (testemunha). Os produtos naturais inibiram a esporulação de C. eragrostides. O fungo Trichoderma sp., óleo de hortelã e ASM 0,3 foram eficientes em reduzirem a severidade da queima das folhas de inhame. O tempo de inoculação influenciou a severidade da doença, de acordo com o produto testado. Trichoderma sp. foi o tratamento que mais reduziu a severidade da doença $(51 \%)$, sendo este, o tratamento podendo ser recomendado para integrar as táticas de manejo da queima das folhas do inhame.

Palavras-chave:Fungo, extratos vegetais, óleo essencial

\section{ABSTRACT}

Carvalho, V.N.; Amorim, E.P.R.; Peixinho, F.S. Evaluating the efficiency of different methods to control yam leaf blight caused by Curvularia eragrostides. Summa Phytopathologica, v.47, n.1, p.34-37, 2021.

Leaf blight, caused by Curvularia eragrostides, can compromise the production of yam (Dioscorea spp.), a crop of extreme importance for the northeast region of Brazil. Natural products have been efficient in controlling plant diseases due to their fungitoxic action or to the presence of eliciting compounds, reducing the use of pesticides. The objective of this study was to evaluate the effect of different methods to control yam leaf blight caused by $C$. eragrostides. Sporulation of the fungus was analyzed in Petri plates containing PDA medium plus the following products: "manipueira" $(40 \%)$; mint oil $(100 \mu \mathrm{L} / \mathrm{mL})$; garlic, 'São Caetano' melon and yam leaf extracts (20\%); Ecolife ${ }^{\circledR}(2 \%)$; Trichoderma sp. (2.0 g.L $\left.\mathrm{L}^{-1}\right)$, and acibenzolar-S-methyl $\left(0.15\right.$ g. $\mathrm{L}^{-1}$ and $\left.0.3 \mathrm{~g} . \mathrm{L}^{-1}\right)$, separately. Control treatment consisted of a plate containing PDA medium without addition of products. The preventive effect of products on the disease development in vivo was assessed with treatments selected in the in vitro test. In the in vivo experiment, yam plants cv. 'Da Costa', 45 days old, were sprayed with the products selected in the in vitro test at $48 \mathrm{~h}$ and $72 \mathrm{~h}$ before inoculation of the pathogen and mint oil $(100 \mu \mathrm{L})$; garlic and yam leaf extracts $(20 \%)$; Trichoderma sp. $\left(2.0\right.$ g. $\left.\mathrm{L}^{-1}\right)$; acibenzolar-S-methyl ( 0.15 and $\left.0.3 \mathrm{~g} \mathrm{~L}^{-1}\right)$, and water (control). All natural products inhibited $C$. eragrostides sporulation. The best severity reduction was provided by Trichoderma sp. applied at $72 \mathrm{~h}$ before inoculation of the pathogen $(51 \%)$, followed by mint oil at $48 \mathrm{~h}(41.4 \%)$ and $72 \mathrm{~h}(31.5 \%)$, Trichoderma sp. at $48 \mathrm{~h}(31.5 \%)$ and acibenzolar-S-methyl 0.3 g.L. $\mathrm{L}^{-1}$ at $72 \mathrm{~h}$ $(25.5 \%)$. The inoculation time influenced the disease severity according to the tested product. Trichoderma sp. was the treatment that most reduced the disease severity (51\%) and can be recommended to integrate yam leaf blight management strategies.

Keywords: Fungus, plant extracts, essential oil.

A queima das folhas, causada pelo fungo Curvularia eragrostidis (P. Henn.) Meyer, ocorre regularmente nas áreas de produção de inhame, durante todo o ano, dificultando o cultivo (7), por atingir alta incidência e severidade (6), reduzindo em torno de 35 a $40 \%$ o peso de túberas comercial de inhame no Nordeste do Brasil (7).

Apesar da ausência de fungicidas registrados para a cultura, o controle da doença é realizado utilizando-se produtos à base de mancozeb, triadimenol e tebuconazole (4). A restrição ao uso de fungicidas, devido à falta de registro, fitotoxicidade, efeitos residuais, espectro de ação e resistência adquirida pelo patógeno, tem levado à procura de métodos alternativos de controle, tais como, uso de biofungicidas, extratos vegetais e óleos essenciais, entre os quais se 
destacam: Ecolife ${ }^{\circledR}$ (produto a base de biomassa cítrica), manipueira (extrato líquido das raízes de cassava, Manihot esculenta Crantz), óleo essencial de hortelã-pimenta (Mentha piperita L.), os extratos de alho (Allium sativum L.), de melão de São Caetaneo (Momordica charantia L.) e de folhas de inhame (Dioscorea sp.) (2).

Essas substâncias já foram testadas sobre fungos fitopatogênicos, com resultados promissores em diversas culturas, agindo como pesticidas agrícolas naturais ou como indutores de resistência (3). Assim, o objetivo deste trabalho foi avaliar o efeito de diferentes formas de controle da queima das folhas do inhame causado por Curvularia eragrostides.

\section{MATERIAL E MÉTODOS}

Os dois experimentos foram conduzidos no laboratório de Fitopatologia e casa-de-vegetação, respectivamente, do Centro de Ciências Agrárias da Universidade Federal de Alagoas, em Rio Largo (AL). No primeiro foi avaliado a inibição da esporulação de $C$. eragrostides, in vitro, enquanto no segundo, avaliou-se os tratamentos em condições de pré- colheita.

Para obtenção do isolado foram realizadas visitas a propriedades produtoras de inhame em Chã Preta, Alagoas, onde foram feitas coletas de materiais vegetais com sintomas característicos da Queima das folhas. Fragmentos de folhas doentes foram desinfestados em hipoclorito de sódio a 1,5\%, e em seguida lavados em água destilada esterilizada, colocados em placas de Petri contendo o meio batatadextrose-ágar (BDA) e incubados, por cinco dias, sob alternância luminosa de 12 horas, sob condições ambientais $\left(28 \pm 2{ }^{\circ} \mathrm{C}\right)$ até o surgimento das colônias características do fungo, aproximandamente 10 dias. Após a confirmação do agente causal, pela observação microscópica de estruturas reprodutivas, o isolado foi transferido para tubos de ensaio contendo BDA.

Com o objetivo de se avaliar a inibição da esporulação de $C$. eragrostides, in vitro, os produtos naturais foram adicionados ao meio de cultura BDA, fundente $\left(45-50{ }^{\circ} \mathrm{C}\right)$ e vertidos em placas de Petri de $9 \mathrm{~cm}$ de diâmetro, nas concentrações: $40 \%$ (manipueira); $100 \mu \mathrm{L}$ para o óleo de hortelã, $20 \%$ para o extrato de alho, $20 \%$ para o extrato de melão de São Caetano e $20 \%$ do extrato da própria folha de inhame; $2 \%$ (Ecolife $\left.{ }^{\circledR}\right) ; 2,0$ g.L ${ }^{-1}$ (Trichoderma sp.); 0,15 g.L -1 $^{-1}$ e 0,3 g.L L $^{-1}$ (acibenzolar-S-metil-ASM) e testemunha (BDA). Os produtos naturais foram esterilizados pela ação de luz UV contínua por 30 minutos antes de serem adicionados ao meio autoclavado.

No centro de cada placa foi depositado um disco de meio BDA de 0,6 cm de diâmetro, contendo micélio fúngico, retirado das bordas da colônia do patógeno. Após a incubação por sete dias à temperatura de $28{ }^{\circ} \mathrm{C}$ e fotoperíodo de 12 horas, foi determinado a porcentagem de inibição da esporulação do fungo (PIE), pela diferença entre a esporulação da testemunha e a esporulação do tratamento dividido pela esporulação da testemunha, multiplicado por 100 (5), expresso por:

$$
\text { P.I.C. }=\frac{(\text { esporulação testemunha }- \text { esporulação tratamento }) * 100}{\text { Esporulação testemunha. }}
$$

O delineamento experimental utilizado foi o inteiramente casualizado, com 10 tratamentos e 4 repetições (placas). Os valores obtidos foram submetidos a análise de variância, teste $\mathrm{F}$, e quando os efeitos de tratamentos apresentaram diferença significativa $(\mathrm{P}<0,01)$, as médias foram comparadas pelo teste de Tukey a $5 \%$ de probabilidade.

Em casa-de-vegetação foram selecionados os tratamentos com melhor desempenho nos ensaios preliminares in vitro, foram utilizados, portanto, os seguintes tratamentos: óleo de hortelã ( $100 \mu \mathrm{L})$; extrato de alho e de folhas de inhame (20\%); Trichoderma sp. (2,0 g.L - $\left.^{-1}\right)$; ASM $\left(0,15 \mathrm{~g}\right.$. $\mathrm{L}^{-1}$ e $\left.0,3 \mathrm{~g} \mathrm{~L}^{-1}\right)$ e água (testemunha). Os tubérculos de inhame cv. Da Costa foram plantadas em vasos (3L) contendo substrato de plantio esterilizado e após desenvolvimento vegetativo (45 dias), as plantas de inhame foram pulverizadas ( $10 \mathrm{~mL} /$ planta), dois e quatro dias antes da inoculação do patógeno com os tratamentos.

As plantas foram inoculadas com uma suspensão de C. eragrostides, $10 \mathrm{ml} /$ planta $\left(1,7 \times 10^{6} \mathrm{con} \cdot \mathrm{mL}^{-1}\right)$. A severidade da doença foi avaliada 15 dias após a inoculação, utilizando uma escala diagramática estabelecida por (6), indicando níveis de $0,1,2,4,8,16,24$ e $32 \%$ de severidade, onde avaliou-se a severidade de 24 folhas/planta.

$\mathrm{O}$ delineamento experimental foi inteiramente casualizado, em esquema fatorial $7 \times 2+$ Testemunha ( 7 produtos e 2 época de tratamento) com quinze tratamentos e quatro repetições. Os dados foram submetidos à análise de variância e as médias comparadas pelo teste de Tukey $(\mathrm{P} \leq 0,05)$.

\section{RESULTADOS E DISCUSSÃO}

De acordo com os dados apresentados na Tabela 1, todos os tratamentos diferiram da testemunha e foram capazes de inibir a esporulação do fungo, em maior ou menor grau a depender da substância testada. O óleo de hortelã, os extratos vegetais de alho, melão de São Caetano e o fungo Trichoderma sp. inibiram totalmente a esporulação do patógeno (100\%), seguidos de extrato de folha de inhame (72\%), Ecolife $^{\circledR}(55 \%)$ e manipueira (45\%). O indutor de resistência ASM, nas duas concentrações, foi o que apresentou a menor PIE, respectivamente 20 e $30 \%$.

Alguns pesquisadores justificam a ação desses produtos naturais baseados na composição bioquímica destes. Conforme Furtado (3), os óleos essenciais têm ação bactericida, fungicida e inseticida, possuindo determinados terpenos que são capazes de tornarem a membrana celular do fungo permeável, causando vazamento de seu conteúdo.

De acordo com Ponte (8), os compostos cianogênicos e a variada composição química presentes na manipueira (subproduto ou resíduo obtido após a prensagem das raízes da mandioca) justificam a sua ação nematicida, fungicida, inseticida, herbicida etc. Já o Ecolife ${ }^{\circledR}$ tem sua capacidade de ação devido à presença de compostos fenólicos (bioflavonóides, fitoalexinas e polifenóis) e ácidos orgânicos (ascórbico lático e cítrico) (9).Almeida et al. (1), observaram inibição do crescimento micelial, taxas de esporulação e de germinação de esporos de Curvularia eragrostidis e Phyllostica sp., ao analisarem quatro extratos vegetais, entre eles a manipueira a partir da concentração de $5 \%$ e concluíram que as inibições aumentaram para valores próximos a $100 \%$ em concentrações acima de $25 \%$.

Com relação à severidade da doença, os produtos naturais a base de folhas de inhame, hortelã e melão de são caetano inibiram a esporulação de C. eragrostides. O fungo Trichoderma sp., óleo de hortelã e ASM 0,3, aplicados 48 e 72 hs antes da inoculação do patógeno, foram eficientes na redução da severidade da queima das folhas de inhame, diferindo significativamente dos demais tratamentos. O tempo de inoculação influenciou a severidade da doença, de acordo com os produtos testados. A maior redução da severidade foi proporcionada por Trichoderma sp., quando aplicado $72 \mathrm{~h}$ antes da inoculação do patógeno (51\%), seguido do óleo de hortelã 48 h (41,4\%), e 72 h (31,5 $\%)$, Trichoderma sp. 48 h (31,5\%) e ASM 0,3, 72 h (25,5\%). Os demais tratamentos não diferiram da Testemunha (Figura 1). 
Tabela 1. Efeito de produtos naturais sobre a esporulação de Curvularia eragrostides. Médias seguidas por mesma letra, não diferem entre si, pelo teste de Tukey a $5 \%$ de probabilidade.

\begin{tabular}{ccc}
\hline Produtos naturais & \% de inibição de Esporulação \\
\hline Manipueira & $47 \quad \mathrm{c}$ \\
Hortelã & $100 \mathrm{a}$ & \\
Alho & $100 \mathrm{a}$ & \\
Melão de são caetano & $100 \mathrm{a}$ & \\
Ecolife & 55 & $\mathrm{c}$ \\
Extrato de Folha de inhame & $71 \quad \mathrm{~b}$ & \\
Trichoderma sp & $100 \mathrm{a}$ & \\
ASM 0,15 g.L $\mathrm{L}^{-1}$ & 20 & $\mathrm{~d}$ \\
ASM 0,3 g.L $\mathrm{L}^{-1}$ & 30 & $\mathrm{~d}$ \\
Testemunha & 0 & $\mathrm{~d}$ \\
\hline
\end{tabular}

Macedo (5) estudando o efeito de produtos vegetais e Ecolife ${ }^{\circledR}$ no controle da antracnose (C. gloeosporioides) no mamoeiro, destaca o alho, na concentração de $10 \%$, como o melhor resultado, ao obter índice de doença de $16,5 \%$, conseguindo controlar a doença em $81,14 \%$.

Almeida et al (1) utilizando extratos vegetais na proteção de plantas de inhame contra C. eragrostidis e Phyllosticta sp. observaram que houve redução da incidência dos dois patógenos para as diferentes concentrações dos extratos testados quando comparados com a testemunha, e as menores médias da área da curva de progresso da doença foram obtidas quando utilizou-se manipueira, e folhas de juá a $25 \%$, discordando dos resultados encontrados nesse trabalho. Um dos principais fatores para essa discordância encontra-se na manipulação e no armazenamento da manipueira, visto que ao decorrer do tempo a concentração do ácido cianídrico diminui em virtude da liberação de $\mathrm{CN}$ livre e aumento do $\mathrm{pH}$ da solução.

Sales (10), trabalhando em casa de vegetação com C. eragrostides, salientou o potencial do extrato de alho e do fungo Trichoderma sp. para o controle da queima das folhas de inhame, concordando parcialmente com os resultados encontrados nesse trabalho, tendo em vista que, o extrato de alho não diferiu estatisticamente da testemunha. Provavelmente as diferenças observadas estejam relacionadas ao local de execução dos experimentos e aos produtos testados (forma de manipulação, estado de maturação, método de extração, etc).

Com os resultados obtidos neste trabalho, conclui-se que o óleo de hortelã, a manipueira, os extratos de alho, melão de São Caetano, inhame, Ecolife ${ }^{\circledR}$ e o fungo Trichoderma possuem capacidade de inibir a esporulação de $C$. eragrostides. O fungo Trichoderma sp., o óleo de hortelã e o ASM 0,30, aplicados 72 ou 48 h antes da inoculação do patógeno reduzem a severidade da queima das folhas de inhame. Trichoderma sp. foi o tratamento que mais reduziu a severidade da doença $(51 \%)$, sendo este, o tratamento recomendado para o manejo da queima das folhas do inhame.

Estudos mais detalhados, e em condições diferentes são necessários para a confirmação da eficiência desses produtos no controle da queima das folhas do inhame.

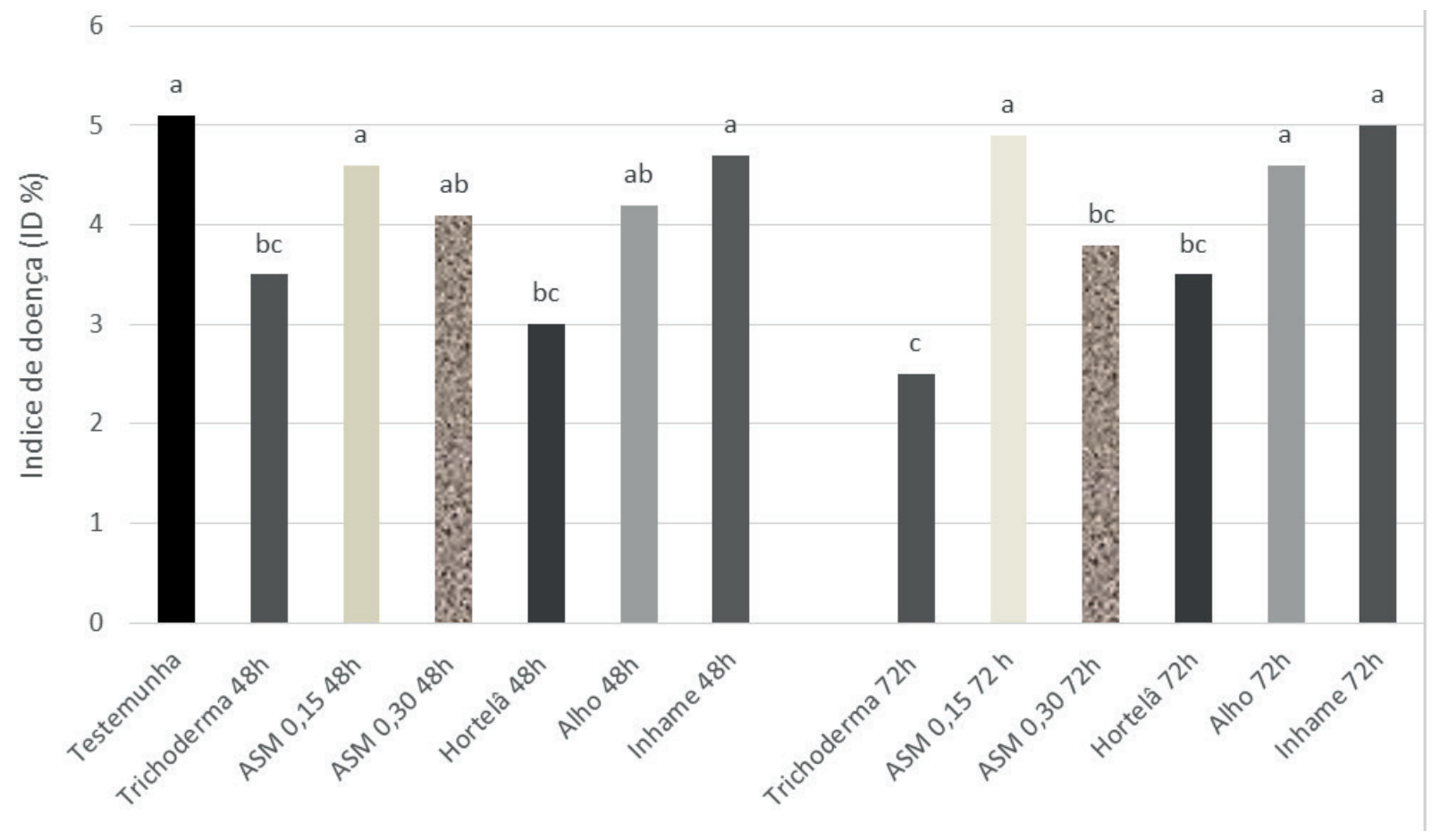

Figura 1. Efeito preventivo de diferentes produtos sobre a severidade da queima das folhas do inhame.

\section{REFERÊNCIAS}

1. ALMEIDA, D. O. C. de; SOUZA, J. T. de; MOREIRA, R. F. C. Uso de extratos vegetais na proteção de plantas de inhame contra Curvularia eragrostidis e Phyllosticta sp. Agrotrópica. Ilhéus, Bahia; Centro de Pesquisas do Cacau, 2013.

2. CARVALHO, R. A.; LACERDA, J. T. de; OLIVEIRA, E. F. de; SANTOS,
E. S. dos. Extratos de plantas medicinais como estratégia para o controle de doenças fúngicas do inhame (Dioscorea sp.) no nordeste. 2013.

3. FURTADO, D. C. Efeito de óleos essenciais e extratos vegetais no controle de fusarium semitectum, Colletotrichum gloeosporioides, Curvularia luneta e C. eraglostides em inflorescências de tapeinochillus anannaceae. Dissertação (Mestrado) - Universidade Federal de Alagoas. Rio Largo. 61p, 2006.

4. KIMATI, H. et al. Manual de Fitopatologia: doenças das plantas culti- 
vadas. 4. Ed. São Paulo: Agronômica Ceres. P.415-419, 2005.

5. MACEDO, J. J. N. de. Efeito de produtos naturais e Ecolife sobre Colletotrichum gloesporioides, os níveis de antracnose e qualidade dos frutos Sunrise Golden. 2013. 50p. Dissertação (Mestrado em proteção vegetal) - Universidade Federal de Alagoas, Rio Largo, 2013.

6. MICHEREF, S.J; MAFFIA, L. A.; NORONHA, M. A. Progresso e arranjo espacial da queima das folhas do inhame, causadas por Curvularia eragrostides, na Zona da mata de Pernambuco Agrotrópica, Ilhéus, v.12, n. 2, p. 87-94, 2000.
7. MOURA, R.M. Doenças do inhame-da-costa (Dioscorea cayennensis). In: Kimati, H., Amorim, L., Rezende, J.A.M., Bergamin Filho, A. \& Camargo, L.E.A. Manual de fitopatologia: doenças das plantas cultivadas. $4^{\mathrm{a}} \mathrm{ed}$ v.2. São Paulo. Agronômica Ceres. pg.415-419. 2005.

8. PONTE, J. J. Cartilha da manipueira: uso do composto como insumo agrícola. Secretaria da Ciência e Tecnologia do Ceará, 53p. 1999.

9. QUINABRA- Química Natural Brasileira Ltda. 2005. Disponível em <www.quinabra.com.br> Acessado em: 01/03/2016.

10. SALES, M. E. F. Avaliação de produtos naturais no controle da Queima das folhas do Inhame (Curvularia eragrostides (Henn.) Meyer). Dissertação (Mestrado). Universidade Federal de Alagoas. Rio Largo. 61p, 2014. 